\title{
The metabolic syndrome of fructose-fed rats: Effects of long-chain polyunsaturated $\omega 3$ and $\omega 6$ fatty acids. III. Secretory behaviour of isolated pancreatic islets
}

\author{
ZOHEIR MELLOUK $^{1}$, YING ZHANG ${ }^{2}$, NURDAN BULUR ${ }^{2}$, KARIM LOUCHAMI $^{2}$, \\ WILLY J. MALAISSE ${ }^{2}$, DALILA AIT YAHIA ${ }^{1}$ and ABDULLAH SENER ${ }^{2}$ \\ ${ }^{1}$ Department of Biology, Es-Sénia University, Oran, Algeria; ${ }^{2}$ Laboratory of Experimental \\ Hormonology, Université Libre de Bruxelles, Brussels, Belgium
}

Received July 6, 2011; Accepted September 2, 2011

DOI: $10.3892 /$ ijmm.2011.812

\begin{abstract}
In the present study, rats were exposed from the 8th week after birth and for the ensuing 8 weeks to diets containing either starch or fructose $(64 \% \mathrm{w} / \mathrm{w})$ and sunflower oil (5\%). Two further groups of rats were exposed to the fructose-containing diet with substitution of part $(1.6 \%)$ of the sunflower diet by an equal amount of either salmon oil rich in long-chain polyunsaturated $\omega 3$ fatty acids or safflower oil reach in longchain polyunsaturated $\omega 6$ fatty acids. The insulin content of the islets and their secretory response to D-glucose $(5.6,8.3$ and $16.7 \mathrm{mM})$, to the combination of D-glucose $(5.6 \mathrm{mM})$ and D-fructose $(10.0 \mathrm{mM})$ and to 2-ketoisocaproate $(10.0 \mathrm{mM})$ were then measured. In the sunflower oil-fed rats, the dietary substitution of starch by fructose decreased basal insulin output, lowered the apparent $\mathrm{Km}$ for the insulinotropic action of D-glucose and altered the insulinotropic efficiency of the latter hexose relative to that of other nutrients. Some of these secretory perturbations were opposed by the enrichment of the diet in long-chain polyunsaturated fatty acids, especially $\omega 3$ fatty acids. It is proposed that these changes in B-cell secretory behaviour may be linked, in part at least, to both the apparent caloric efficiency of each diet, and hence to the regulation of the islet content in endogenous nutrients, and to alteration of insulin sensitivity considered as a major feature of the present animal model of metabolic syndrome.
\end{abstract}

\section{Introduction}

In the two preceding reports in this series $(1,2)$, attention was mainly drawn to the perturbation of glucose homeostasis

Correspondence to: Correspondence to: Professor Willy J. Malaisse, Laboratory of Experimental Hormonology, Université Libre de Bruxelles, 808 Route de Lennik, B-1070 Brussels, Belgium E-mail:malaisse@ulb.ac.be

Key words: metabolic syndrome, fructose-fed rats, long-chain polyunsaturated $\omega 3$ and $\omega 6$ fatty acids, pancreatic islet insulin secretion and content found in rats exposed to diets containing sunflower oil and either starch or D-fructose as the source of carbohydrates and in fructose-fed rats exposed to diets enriched in either $\omega 3$ fatty acids rats or $\mathrm{C} 18: 2 \omega 6$ rats. The present report deals with the insulin secretory behaviour of pancreatic islets isolated from the same four groups of rats.

\section{Materials and methods}

The four groups of rats examined in this study were defined in the second report in this series (1). The methods used to measure insulin release over $90 \mathrm{~min}$ incubation at $37^{\circ} \mathrm{C}$ and the final insulin content of the islets were previously described (3). Briefly, groups of 8 islets each were incubated for $90 \mathrm{~min}$ at $37^{\circ} \mathrm{C}$ in $1.0 \mathrm{ml}$ of a salt-balanced medium (4) containing $0.5 \mathrm{mg} / \mathrm{ml}$ bovine serum albumin and equilibrated against a mixture of $\mathrm{O}_{2} / \mathrm{CO}_{2}(95 / 5, \mathrm{v} / \mathrm{v})$. After incubation, the islets were examined for their insulin content. The insulin and protein content (5) of freshly isolated islets was also measured. All results are expressed as mean values $( \pm$ SEM) together with the number of individual determinations (n) or degree of freedom (df). The statistical significance of difference between mean values was assessed by use of Student's t test.

\section{Results}

Insulin release recorded in the presence of $5.6 \mathrm{mM} D$-glucose. As documented in Table I, the close-to-basal release of insulin recorded over $90 \mathrm{~min}$ incubation in the presence of $5.6 \mathrm{mM}$ D-glucose was somewhat higher $(\mathrm{p}<0.04)$ in the $(\mathrm{Ssun})$ rats than in the 3 groups of fructose-fed animals. Pooling together all available data, it averaged $51.4 \pm 4.2 \mu \mathrm{U} /$ islet per $90 \mathrm{~min}$ $(n=67)$.

Insulin release recorded in the presence of both $5.6 \mathrm{mM}$ $D$-glucose and $10.0 \mathrm{mM}$ D-fructose. The increment in insulin output caused by $10.0 \mathrm{mM}$ D-fructose in islets also exposed to $5.6 \mathrm{mM}$ D-glucose was highly significant in all cases $(\mathrm{p}<0.005$ or less), whether expressed in absolute or relative terms (Table I). In absolute terms, such an increment was significantly lower ( $p<0.02$ or less) in the fructose-exposed 
Table I. Insulin output.

\begin{tabular}{|c|c|c|c|c|}
\hline Rats & Ssun & Fsun & Fsal & Fsaf \\
\hline & \multicolumn{2}{|c|}{ Insulin output ( $\mu \mathrm{U} /$ islet per $90 \mathrm{~min})$} & & \\
\hline D-glucose $5.6 \mathrm{mM}$ & $77.8 \pm 12.9(16)$ & $35.6 \pm 6.1(16)$ & $46.7 \pm 5.9(18)$ & $46.5 \pm 3.7(17)$ \\
\hline D-glucose $5.6 \mathrm{mM}+\mathrm{D}$-fructose $10.0 \mathrm{mM}$ & $170.8 \pm 23.9(20)$ & $75.5 \pm 6.4(15)$ & $117.6 \pm 20.4(18)$ & $77.9 \pm 10.5(17)$ \\
\hline D-glucose $8.3 \mathrm{mM}$ & $91.8 \pm 9.1(19)$ & $58.8 \pm 9.1(17)$ & $71.8 \pm 7.0(18)$ & $59.3 \pm 4.7(17)$ \\
\hline D-glucose $16.7 \mathrm{mM}$ & $185.2 \pm 15.4(20)$ & $101.2 \pm 13.5(17)$ & $170.5 \pm 21.7(19)$ & $147.6 \pm 18.4(16)$ \\
\hline 2-ketoisocaproate $10.0 \mathrm{mM}$ & $83.5 \pm 9.4(20)$ & $60.1 \pm 10.4(17)$ & $68.4 \pm 8.3(19)$ & $54.5 \pm 3.9(17)$ \\
\hline
\end{tabular}

Increment in insulin output

$(\mu \mathrm{U} / \text { islet per } 90 \mathrm{~min})^{\mathrm{a}}$

\begin{tabular}{|c|c|c|c|c|}
\hline \multirow[b]{2}{*}{$\Delta 10.0 \mathrm{mM}$ D-fructose } & & \multirow[b]{2}{*}{$65.5 \pm 16.9(30)$} & \multirow[b]{2}{*}{$31.5 \pm 10.6(28)$} \\
\hline & $92.5 \pm 16.9(30)$ & $38.3 \pm 11.4(25)$ & & \\
\hline$\Delta 8.3 \mathrm{mM}$ D-glucose & $11.3 \pm 7.6(29)$ & $24.4 \pm 6.7(27)$ & $24.6 \pm 5.9(30)$ & $12.7 \pm 5.9(28)$ \\
\hline$\Delta 16.7 \mathrm{mM}$ D-glucose & $103.1 \pm 12.2(30)$ & $66.9 \pm 12.4(27)$ & $121.0 \pm 19.1(31)$ & $99.7 \pm 13.0(27)$ \\
\hline$\Delta 10.0 \mathrm{mM}$ 2-ketoisocaproate & $1.8 \pm 8.2(30)$ & $25.2 \pm 8.8(27)$ & $19.6 \pm 6.6(31)$ & $7.9 \pm 5.2(28)$ \\
\hline
\end{tabular}

Increment in insulin output (\%)

$\Delta 10.0 \mathrm{mM}$ D-fructose

$112.3 \pm 20.7(30)$

$89.0 \pm 25.6(25)$

$125.4 \pm 24.1(30)$

$67.0 \pm 21.4(28)$

$\Delta 8.3 \mathrm{mM}$ D-glucose

$39.2 \pm 11.5(29)$

$68.8 \pm 19.0(27)$

$63.5 \pm 15.3(30)$

$29.9 \pm 12.8(28)$

$\Delta 16.7 \mathrm{mM}$ D-glucose

$197.3 \pm 36.9(30)$

$216.8 \pm 39.4(27)$

$261.8 \pm 29.7(31)$

$211.8 \pm 34.8(27)$

$\Delta 10.0 \mathrm{mM}$ 2-ketoisocaproate

$15.8 \pm 11.1(30)$

$72.8 \pm 21.2(27)$

$42.0 \pm 11.8(31)$

$18.9 \pm 19.1(28)$

${ }^{a}$ The increments in insulin output refer to the difference found in each experiment above the mean corresponding value recorded in the presence of $5.6 \mathrm{mM}$ D-glucose.

rats than in the (Ssun) rats, whether the diet of the former rats was enriched or not with $\omega 6$ fatty acid. As a matter of fact, there was no significant difference $(\mathrm{p}>0.67)$ between these two groups of rats, with an overall mean value for the D-fructoseinduced increment in insulin output of $34.7 \pm 7.7 \mu \mathrm{U} /$ islet per $90 \mathrm{~min}(\mathrm{df}=53)$ as distinct $(\mathrm{p}<0.001)$ from $92.5 \pm 16.9 \mu \mathrm{U} /$ islet per $90 \mathrm{~min}(\mathrm{df}=30)$ in the control animals. In the (Fsal) rats, the D-fructose-induced increment in insulin output averaged $65.5 \pm 16.9 \mu \mathrm{U} /$ islet per $90 \mathrm{~min}(\mathrm{df}=30)$. It was thus higher albeit not quite significantly so $(\mathrm{p}<0.07)$, than that recorded in the (Fsun) or (Fsaf) rats and no more significantly different ( $p>0.26)$ from the D-fructose-induced increment in insulin output recorded in the (Ssun) rats.

Essentially comparable information was reached when considering the relative values for the D-fructose-induced increment in insulin output (Table I). Briefly, such relative increment yielded mean values comparable in (Ssun) rats $(112.3 \pm 20.7 \% ; \mathrm{df}=30)$ and (Fsal) rats $(125.4 \pm 2.41 \% ; \mathrm{df}=30)$ and lower values in the (Fsun) rats $(89.0 \pm 25.6 \%$; $\mathrm{df}=25)$ or (Fsaf) rats $(67.0 \pm 21.4 \%$; $\mathrm{df}=28)$. The difference between the mean values found in the former 2 groups of rats $(118.8 \pm 15.8 \%$; $\mathrm{df}=60)$ and latter 2 groups of rats $(77.4 \pm 16.5 \% ; \mathrm{df}=53)$ was close to achieving statistical significance $(\mathrm{p}<0.08)$.

Insulin release recorded in the presence of $16.7 \mathrm{mMD}$-glucose. A somewhat different situation prevailed when considering the increment in insulin output evoked by a rise in D-glucose concentration from 5.6 to $16.7 \mathrm{mM}$. In absolute terms, the
D-glucose-induced increment in insulin output in the (Fsun) rats remained lower ( $p<0.05$ or less) than that found in either the (Ssun) or (Fsal) rats, and even became lower $(\mathrm{p}<0.06)$ from that recorded in the (Fsaf) rats. In relative terms, however, the lowest value was recorded in the (Ssun) rats $(197.3 \pm 36.9 \%$; $\mathrm{df}=30$ ), it being nevertheless not significantly difference ( $>0.35$ ) from the mean value found in the other 3 groups of rats $(231.5 \pm 19.8 \%$; $\mathrm{df}=85)$.

The difference between the diet-induced changes in the secretory response to D-fructose, on one hand, and a rise in D-glucose concentration from 5.6 to $16.7 \mathrm{mM}$, in the other hand, was best documented by the ratio between corresponding variables in these two instances. Indeed, in this respect, comparable results were obtained for i) the ratio between the mean values for the absolute increments in insulin output, ii) the ratio between the mean values for the relative increments in insulin release, and iii) the paired ratio in each individual experiment between the increments in insulin secretion. As illustrated in Fig. 1, the ratio between the secretory response to the rise in D-glucose concentration and that to D-fructose yielded, as judged by these three criteria, higher mean values in the 3 groups of fructose-exposed rats than in (Ssun) animals. More precisely, the concerned ratio, when compared to that recorded in the (Ssun) animals, was not significantly higher $(\mathrm{p}<0.1)$ in the (Fsal) rats, close to being significantly higher $(\mathrm{p}<0.06)$ in the (Fsun) rats, and obviously higher $(\mathrm{p}<0.005)$ in the (Fsaf) rats. No significant difference ( $p>0.16$ ) was observed between the latter two groups of rats with an overall mean value (expressed 


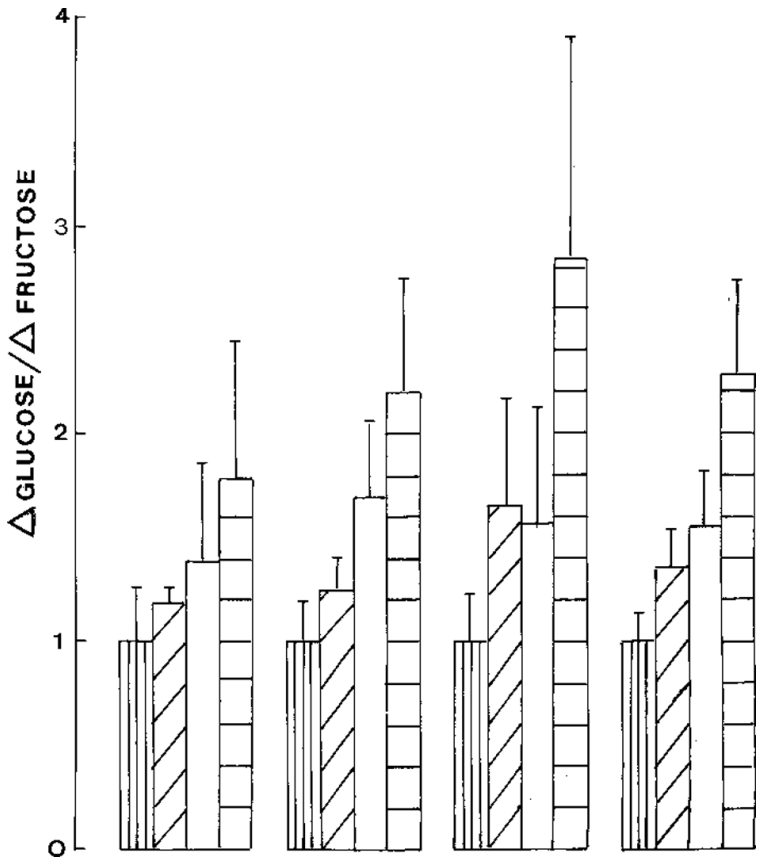

Figure 1. Ratio between the increments in insulin output above the close-tobasal value recorded at $5.6 \mathrm{mM}$ D-glucose caused either by a rise in D-glucose concentration to $16.7 \mathrm{mM}$ or by the incorporation of $10.0 \mathrm{mM}$ D-fructose in the incubation medium in (Ssun) rats (vertically hatched columns), (Fsal) rats (obliquely hatched columns), (Fsun) rats (open columns) or (Fsaf) rats (horizontally hatched columns). Mean values ( \pm SEM; df=27-31) refer from left to right to the ratio between the mean values for the absolute increments in insulin output, the ratio between the mean values for the relative increments in insulin output, the paired ratio in each individual experiment between the increments in insulin secretion, and the overall mean value derived from the former three ratios $(\mathrm{df}=87-90)$, the mean measurements collected in the (Ssun) rats being in all cases taken as the unity reference value.

by reference to the control animals) amounting to $191.4 \pm 26.2 \%$, as distinct $(\mathrm{p}<0.04)$ from only $136.1 \pm 17.4 \%$ in the (Fsal) rats.

The diet-induced changes in the secretory response to $16.7 \mathrm{mM} \mathrm{D}$-glucose, as distinct from the combination of $5.6 \mathrm{mM}$ D-glucose and $10.0 \mathrm{mM}$ D-fructose, were also documented by comparing the absolute values for insulin output under these two experimental conditions. Whilst, in the (Ssun) rats, the ratio in secretory rate between the mean values recorded in the latter/former experimental conditions averaged $92.2 \pm 12.9 \%(\mathrm{n}=20)$, as compared $(\mathrm{p}>0.5)$ to a reference value of $100.0 \pm 8.3 \%(n=20)$, it did not exceed in the 3 groups of fructose-fed rats $65.2 \pm 6.9 \%(\mathrm{n}=50)$ as compared $(\mathrm{p}<0.001)$ to a reference value of $100.0 \pm 7.9 \%(\mathrm{n}=52)$. The difference between $92.2 \pm 12.9 \%(\mathrm{n}=20)$ and $65.2 \pm 6.9 \%(\mathrm{n}=50)$ yielded a probability $(<0.06)$ close to the conventional level of statistical significance. In such a respect, the mean values recorded in the (Fsun) rats (74.6 $\pm 16.3 \%$; $\mathrm{n}=15$ ) were higher, albeit not significantly so, than in the (Fsal) rats $(69.0 \pm 12.0 \% ; \mathrm{n}=18)$ or (Fsaf) rats $(52.8 \pm 7.1 \%$; $\mathrm{n}=17)$. Taken as a whole, these converging findings suggest that the replacement of starch by D-fructose in the diet impaired more severely the secretory response to the ketohexose than that to the aldohexose.

Insulin release recorded in the presence of $8.3 \mathrm{mM} D$-glucose. Whether expressed in absolute or relative terms, the increase in insulin output evoked by a rise in D-glucose concentration

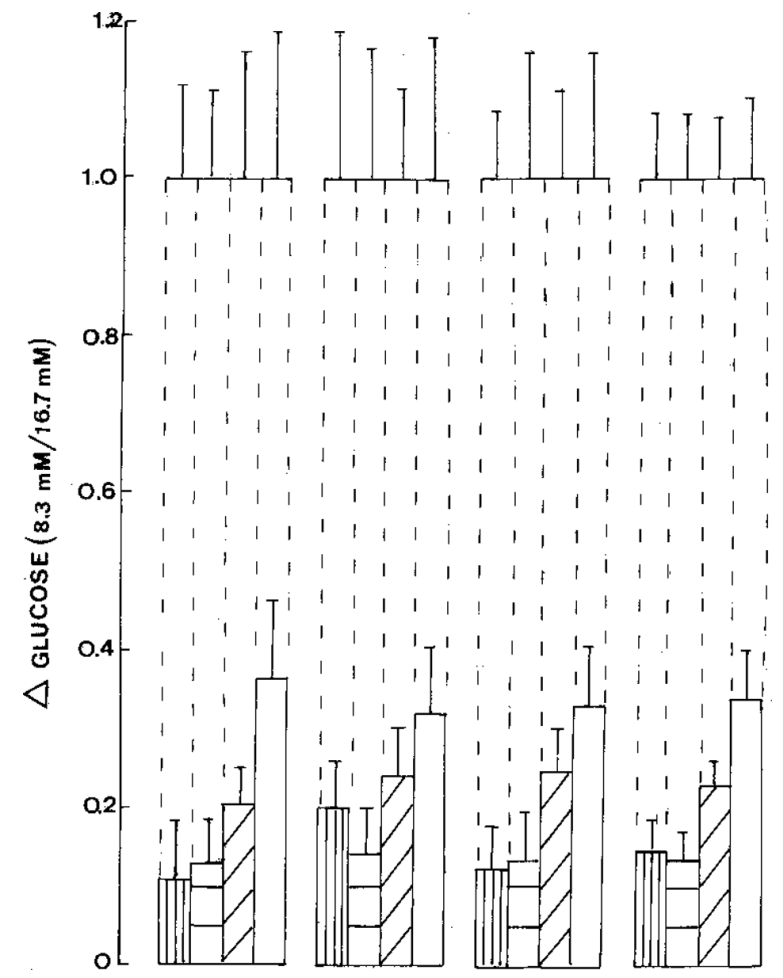

Figure 2. Increments in insulin output evoked by a rise in D-glucose concentration from 5.6 to $8.3 \mathrm{mM}$, expressed relative to those provoked by a rise in D-glucose concentration from 5.6 to 16.7 mM. Same presentation as in Fig. 1.

from 5.6 to $8.3 \mathrm{mM}$ failed to differ significantly in the 4 groups of rats considered in the present study, with overall mean values $(\mathrm{df}=114)$ of $18.2 \pm 3.3 \mu \mathrm{U} /$ islet per $90 \mathrm{~min}(\mathrm{p}<0.001)$ and $50.3 \pm 7.5 \%(\mathrm{p}<0.001)$. The latter relative increment achieved statistical significance ( $<0.03$ or less) in all 4 groups of rats.

When the increments in insulin output evoked by a rise in D-glucose concentration from $5.6 \mathrm{mM}$ to $8.3 \mathrm{mM}$ were expressed relative to those provoked by a rise in the D-glucose concentration from 5.6 to $16.7 \mathrm{mM}$, a comparable hierarchy between the 4 groups of rats was observed, whether the results under consideration referred to the mean absolute increments in insulin output, mean relative increments in insulin output, or paired ratio in each individual experiment between the increments in insulin output under consideration. Thus, as illustrated in Fig. 2, the overall mean values derived from these three criteria averaged $14.6 \pm 3.8 \%(\mathrm{df}=77)$ in the (Ssun) animals, $13.4 \pm 3.5 \%(\mathrm{df}=73)$ in the (Fsaf) rats, $22.8 \pm 3.2 \%$ $(\mathrm{df}=78)$ in the (Fsal) rats and $33.9 \pm 5.4 \%(\mathrm{df}=71)$ in the (Fsun) rats. The highly significant difference $(\mathrm{p}<0.005)$ between the first and last of these mean percentages suggests that chronic exposure to a fructose-rich diet lowered the apparent $\mathrm{Km}$ for the insulin secretory response of the islets to increasing concentrations of extracellular D-glucose. Incidentally, in this comparison between the secretory rates recorded at 8.3 and $16.7 \mathrm{mM}$ D-glucose, the overall mean reference values averaged $100.0 \pm 8.6 \%(\mathrm{df}=80)$ in the (Ssun) rats, $100.0 \pm 8.3 \%$ $(\mathrm{df}=71)$ in the (Fsaf) rats, $100.0 \pm 7.9 \%(\mathrm{df}=81)$ in the (Fsal) rats, and $100.0 \pm 10.6 \%(\mathrm{df}=71)$ in the (Fsun) rats.

Insulin release recorded in the presence of $10.0 \mathrm{mM} 2$-ketoisocaproate. The secretion of insulin provoked by $10.0 \mathrm{mM}$ 


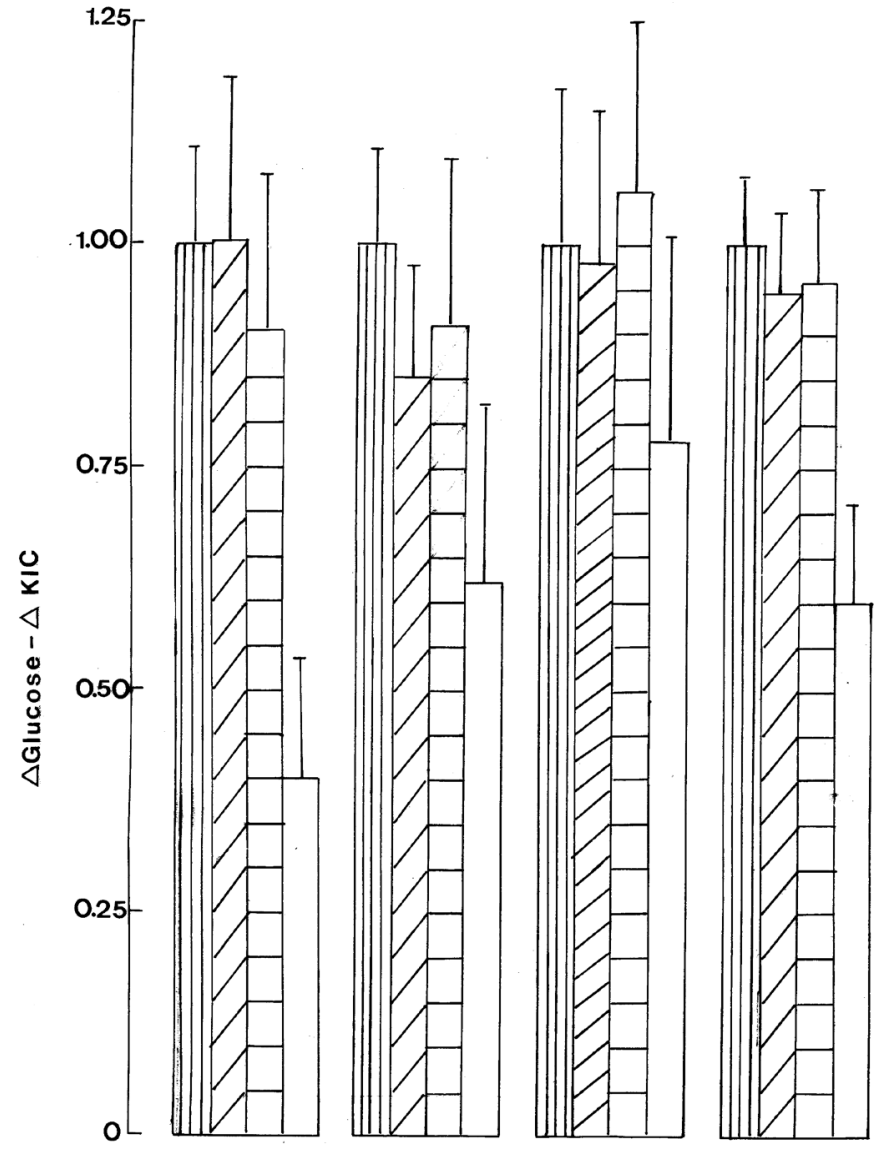

Figure 3. Difference in insulin output between islets exposed to either $10.0 \mathrm{mM}$ 2-ketoisocaproate or $16.7 \mathrm{mM}$ D-glucose and expressed, from left to right, in absolute terms and relative to either the increment in insulin release in response to a rise in D-glucose concentration from 5.6 to $16.7 \mathrm{mM}$ or basal insulin output, all results being illustrated by reference to the mean value found in (Ssun) rats. The last set of columns on the right of the figure refers to the overall mean values derived from the former three comparisons. Same presentation as in Fig. 1.

2-ketoisocaproate, when compared to that recorded within the same experiments in the presence of $5.6 \mathrm{mM}$ D-glucose, yielded mean increments in insulin output not significant difference from one another in the 4 groups of rats, with an overall mean values of $13.5 \pm 3.7 \mu \mathrm{U} /$ islet per $90 \mathrm{~min}(\mathrm{df}=116$; $\mathrm{p}<0.001)$. In this case, the relative increments in insulin output averaged $36.9 \pm 8.2 \%(\mathrm{df}=116 ; \mathrm{p}<0.001)$.

Since the basal release of insulin prevailing in the absence of any exogenous nutrient was not measured in the present experiments, the absolute values for insulin output recorded in the presence of 2-ketoisocaproate $(10.0 \mathrm{mM})$, as measured in the absence of D-glucose, were compared to those found in the presence of 8.3 or $16.7 \mathrm{mM}$ D-glucose.

The absolute values for insulin output recorded in the presence of 2-ketoisocaproate $(10.0 \mathrm{mM})$ were slightly lower $(\mathrm{p}<0.02)$ in the fructose-fed rats $(61.3 \pm 4.6 \mu \mathrm{U} /$ islet per $90 \mathrm{~min}$; $\mathrm{n}=53)$ than in the (Ssun) rats $(83.5 \pm 9.4 \mu \mathrm{U} /$ islet per $90 \mathrm{~min}$; $\mathrm{n}=20$ ). Such was also the case in the islets exposed to $8.3 \mathrm{mM}$ $\mathrm{D}$-glucose with mean values of $91.8 \pm 9.1 \mu \mathrm{U} /$ islet per $90 \mathrm{~min}$; $\mathrm{n}=19)$ in (Ssun) animals, as compared $(\mathrm{p}<0.003)$ to only $63.5 \pm 4.1 \mu \mathrm{U} /$ islet per $90 \mathrm{~min}(\mathrm{n}=52)$ in the fructose-fed rats. As a matter of fact, the absolute values for insulin output in the presence of 2-ketoisocaproate averaged $94.9 \pm 7.2 \%$

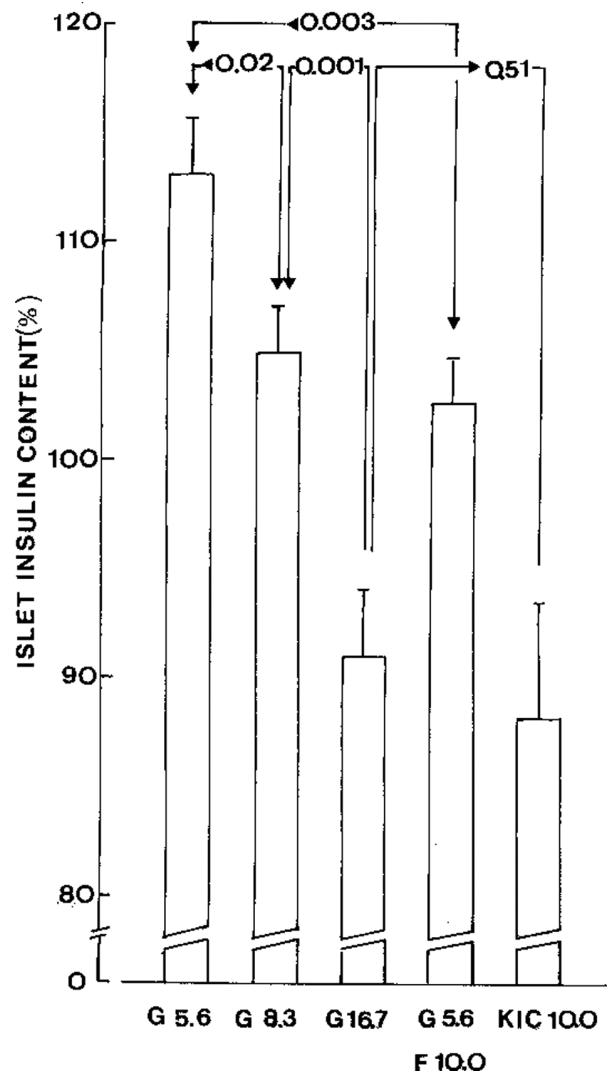

Figure 4. Insulin content of islets first incubated for $90 \mathrm{~min}$ in the presence of D-glucose (G) 5.6, 8.3 or $16.7 \mathrm{mM}$, in the concomitant presence of $5.6 \mathrm{mM}$ D-glucose $(\mathrm{G})$ and $10.0 \mathrm{mM}$ D-fructose $(\mathrm{F})$, and in the presence of $10.0 \mathrm{mM}$ 2-ketoisocaproate (KIC). Mean values $( \pm$ SEM) refer to 74 separate determinations in all cases and are expressed relative to the average derived, in each individual experiment and in islets derived from the same group of rats, from the mean values recorded under the five experimental conditions prevailing during incubation. Also shown are the statistical significance (p) of differences between selected mean values.

$(n=73 ; p>0.57)$ of the mean corresponding values found in the same group of rats in islets exposed to $8.3 \mathrm{mM}$ D-glucose $(100.0 \pm 5.4 \% ; n=71)$. As expected from these findings, the difference found in each experiment $(n=3)$ and in each type of rat between the mean secretory rates recorded in the presence of 2-ketoisocaproate, tested in the absence of D-glucose, and in the presence of only $5.6 \mathrm{mM}$ D-glucose, provided a highly significant $(\mathrm{p}<0.001)$ overall positive average $(+13.5 \pm 3.7 \mu \mathrm{U} /$ islet per $90 \mathrm{~min} ; \mathrm{df}=116$ ). The absolute values for insulin output recorded in the presence of 2-ketoisocaproate, when compared to those found in the presence of $16.7 \mathrm{mM} \mathrm{D}$-glucose also failed to differ significantly ( $>0.29$ or more) in the four groups of rats, with an overall mean values of $45.2 \pm 3.2 \%(n=73)$ relative to the corresponding reference measurements made in the presence of $16.7 \mathrm{mM}$ D-glucose $(100.0 \pm 5.7 \%$; $\mathrm{n}=72)$.

In order to compare the secretory response to 2-ketoisocaproate and $16.7 \mathrm{mM} \mathrm{D}$-glucose, the difference in the absolute values for insulin release under these two experimental conditions were taken into account. As judged from such differences expressed in absolute terms or relative to either the increment in the output attributable to the rise in D-glucose concentration from 5.6 to $16.7 \mathrm{mM}$ or the close-tobasal value for insulin secretion found at $5.6 \mathrm{mM} \mathrm{D}$-glucose, no obvious difference was found between (Ssun) rats and either 
Table II. Insulin and protein content of freshly isolated islets.

\begin{tabular}{lcc}
\hline Rats & Protein content $(\mu \mathrm{g} /$ islet $)$ & Insulin content $(\mu \mathrm{U} /$ islet $)$ \\
\hline Ssun & $3.61 \pm 0.91(4)$ & $444 \pm 69(3)$ \\
Fsun & $3.13 \pm 0.97(2)$ & $501 \pm 7(2)$ \\
Fsal & $2.41 \pm 0.54(3)$ & $380 \pm 70(3)$ \\
Fsaf & $3.00(1)$ & $514 \pm 99(2)$ \\
\hline
\end{tabular}

(Fsal) or (Fsaf) rats (Fig. 3). The results recorded in (Fsun) rats, however, averaged no more than $60.2 \pm 11.0 \%(\mathrm{df}=84$; $\mathrm{p}<0.004)$ of the mean corresponding values found in (Ssun) rats $(100.0 \pm 7.6 \% ; \mathrm{df}=102)$. The results recorded in the former rats also differed significantly from those found in the (Fsal) rats $(94.5 \pm 9.3 \% ; \mathrm{df}=96 ; \mathrm{p}<0.02)$ or (Fsaf) rats $(95.8 \pm 10.7 \%$; $\mathrm{df}=81 ; \mathrm{p}<0.025)$. Considering the lower absolute increments in insulin output provoked by a rise in D-glucose concentration from 5.6 to $16.7 \mathrm{mM}$ in the islets from (Fsun) rats, as compared to (Ssun) rats (see above), the findings illustrated in Fig. 3 duly confirmed that there was no significant difference in the 4 groups of rats under consideration in terms of the islet secretory responsiveness to 2-ketoisocaproate.

Islet insulin content. As indicated in Table II, the mean insulin and protein content of pancreatic islets examined immediately after the isolation failed to differ significantly in the 4 groups of rats, with overall respective mean values of $450 \pm 34 \mu \mathrm{U} /$ islet and 3.09 $\pm 0.42 \mu \mathrm{g} /$ islet ( $\mathrm{n}=10$ in both cases).

Likewise, in islets examined after incubation for $90 \mathrm{~min}$ at $37^{\circ} \mathrm{C}$, the insulin content, expressed relative to the average of the mean islet insulin content found within each experiment and in the four groups of rats after incubation under the same experimental conditions, amounted to $93.6 \pm 2.6 \%(n=100)$ in the (Ssun) rats, $102.3 \pm 2.4 \%(\mathrm{n}=85)$ in the (Fsun) rats, $103.4 \pm 3.0 \%$ $(n=100)$ in the (Fsal) rats, and $99.3 \pm 2.7 \%(n=85)$ in the (Fsaf) rats. Only the first of these four percentages differed significantly $(\mathrm{p}<0.002)$ from that recorded either in the (Fsun) rats or (Fsal) rats. Even so, the quite modest relative magnitude of such differences can obviously not be blamed to any major extent for differences in insulin output in the four groups of rats. Incidentally, the reference values used in these comparisons averaged $528 \pm 36 \mu \mathrm{U} /$ islet $(\mathrm{n}=15)$.

As a rule, the mean values for islet insulin content recorded in each of the four groups of rats for islets first incubated under the same experimental conditions, when expressed relative to the average of the five mean values found in each experiment in islets from the same group of rats first incubated under five distinct experimental conditions (i.e. $528 \pm 43 \mu \mathrm{U} / \mathrm{islet}$; $\mathrm{n}=12$ ), failed to differ significantly from one another. As a matter of fact, among 30 comparisons, only two yielded a significant difference, such being the case in islets from (Ssun) and (Fsaf) rats first incubated at $5.6 \mathrm{mM}$ D-glucose $(\mathrm{df}=35 ; \mathrm{p}<0.05)$ and in islets from (Fsun) and (Fsal) rats first incubated at $16.7 \mathrm{mM}$ D-glucose $(\mathrm{df}=35 ; \mathrm{p}<0.02)$. In light of these findings, the overall mean values found in the four groups of rats were computed for each set of experimental conditions used during incubation. As illustrated in Fig. 4, the islet insulin content progressively decreased from $113.1 \pm 2.6 \%$ to $104.9 \pm 2.2 \%$ and $91.1 \pm 3.0 \%$
( $n=74$ in all cases) as the concentration of D-glucose during incubation increased from 5.6 to 8.3 and $16.7 \mathrm{mM}$. The insulin content was also lower $(\mathrm{p}<0.003)$ in islets first incubated at $5.6 \mathrm{mM} \mathrm{D}$-glucose in the presence, as distinct from absence, of $10.0 \mathrm{mM}$ D-fructose $(102.6 \pm 2.0 \% ; n=74)$. It was comparable in islets first exposed to either $16.7 \mathrm{mM} \mathrm{D}$-glucose or $10.0 \mathrm{mM}$ 2 -ketoisocaproate $(88.2 \pm 3.3 \% ; n=74)$. These differences in islet insulin content obviously represented a mirror image of the differences in insulin output recorded during incubation under the same five distinct experimental conditions.

\section{Discussion}

The mean close-to-basal value for insulin release recorded in islets incubated in the presence of $5.6 \mathrm{mM}$ D-glucose was higher in the (Ssun) rats than in the other groups of rats. In the four groups of rats considered in this study, the mean values for such an insulin output were inversely related $(r=-0.9825$; $\mathrm{n}=4$ ) to the mean corresponding values for the apparent caloric efficiency of the diet. The highest and lowest mean values for insulin release from islets exposed to $5.6 \mathrm{mM}$ D-glucose also coincided, respectively, with the close-to-lowest and highest mean values recorded in the comparison between the increments in insulin output at 8.3/16.7 $\mathrm{mM} \mathrm{D-glucose} \mathrm{(Fig.} \mathrm{2).} \mathrm{These}$ findings are compatible with the view that the apparent caloric efficiency of the diet participates in the regulation of the islet content in endogenous nutrients and, hence, in the relative magnitude of their secretory responsiveness to exogenous nutrients.

The comparison between the increments in insulin output caused by a rise in D-glucose concentration from 5.6 to $16.7 \mathrm{mM}$ or by the addition of $10.0 \mathrm{mM} \mathrm{D}$-fructose to a medium containing 5.6 mM D-glucose convincingly illustrated that the incorporation of large amounts of D-fructose in the diet failed to favour the secretory responsiveness to the ketohexose relative to that to the aldohexose (Fig. 1).

The dietary substitution of starch by D-fructose apparently lowered the postulated $\mathrm{Km}$ for the insulin secretory response to D-glucose (Fig. 2), an effect counteracted by the enrichment of the diet in long-chain polyunsaturated fatty acids, especially

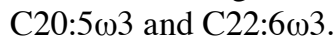

Last, as a rule, the dietary manipulations exerted little effects upon the insulinotropic efficiency of 2-ketoisocaproate, compared to that of D-glucose. At the most, the results illustrated in Fig. 3 suggest that the dietary substitution of starch by $\mathrm{D}$-fructose decreased the insulinotropic efficiency of D-glucose, compared to that of 2-ketoisocaproate. The latter effect was again counteracted by the enrichment of the diet in either C18:2 $\omega 6$ or $\mathrm{C} 20: 5 \omega 3$ and $\mathrm{C} 22: 6 \omega 3$.

It should be stressed that the changes in B-cell secretory behaviour encountered in the present study could not be blamed on any sizeable alteration in the insulin content of the islets. Moreover, the close parallelism observed between the amount of insulin released by the islets during incubation in the presence of different concentrations or combinations of nutrient secretagogues and the corresponding resulting changes in the insulin content of the islets further document the internal consistency of the present secretory data.

Taken as a whole, therefore, the present findings draw attention to three changes in the secretory behaviour of insulin- 
producing cells caused, in sunflower oil-fed rats, by the dietary substitution of starch by D-fructose, namely a decrease in basal insulin output, an apparent lowering of the quoted $\mathrm{Km}$ for the insulinotropic action of D-glucose and an alteration in the insulinotropic efficiency of D-glucose relative to that of other nutrient secretagogues. Some of these secretory perturbations were opposed by the enrichment of the diet in long-chain polyunsaturated fatty acids, especially C20:5 203 and C22:6 133 . To the extent that the latter dietary manipulation also opposed the insulin resistance caused in the present experimental design by the fructose-enriched diet, the above-mentioned changes in B-cell secretory behaviour could be attributable, in part at least, to such an insulin resistance considered as a major feature of the present animal model of metabolic syndrome.

\section{Acknowledgments}

We are grateful to C. Demesmaeker for secretarial help.

\section{References}

1. Mellouk Z, Hachimi Idrissi T, Louchami K, Hupkens E, Malaisse WJ, Ait Yahia D and Sener A: The metabolic syndrome of fructose-fed rats: effects of long-chain polyunsaturated $\omega 3$ and $\omega 6$ fatty acids. I. Intraperitoneal glucose tolerance test. Int $\mathbf{J}$ Mol Med 28: 1087-1092, 2011.

2. Mellouk Z, Hachimi Idrissi T, Louchami K, Hupkens E, Sener A, Ait Yahia D and Malaisse WJ: The metabolic syndrome of fructose-fed rats: effects of long-chain polyunsaturated $\omega 3$ and $\omega 6$ fatty acids. II. Time course of changes in food intake, body weight, plasma glucose and insulin concentrations and insulin resistance. Int J Mol Med 29: 113-118, 2012.

3. Malaisse-Lagae $\mathrm{F}$ and Malaisse WJ: Insulin release by pancreatic islets. In: Methods in Diabetes Research. Larner J and Pohl S (eds). Vol. I, part B, John Wiley \& Sons, New York, pp147-152, 1984.

4. Malaisse WJ, Maggetto C, Leclercq-Meyer V and Sener A: Interference of glycogenolysis with glycolysis in pancreatic islets from glucose-infused rats. J Clin Invest 91: 432-436, 1993.

5. Lowry O, Rosebrough NJ, Farr AL and Randall RJ: Protein measurement by the Folin phenol reagent. J Biol Chem 193: 265-275, 1951. 